\title{
Internal Audit and the Modernization of Moroccan Public Administrations
}

\author{
HAINOUS Mouard ${ }^{1}$, SEKAKI Yassine ${ }^{2}$, AMIRI Imane ${ }^{3}$ and Pr. ZAAM Houria ${ }^{4}$ \\ ${ }^{1,2,3}$ PhD student in management science at Abdelmalek Essaâdi University, Morocco \\ ${ }^{4}$ Professor of Higher Education at the Faculty of Economic and Social Legal Sciences, Tétouan, Morocco
}

\begin{abstract}
The new constitution of 2011 and the Organic Law ${ }^{\circ} 130-13$ related to the Finance law constituted for Morocco a major turning point in the modernization's path of the public administration. A much desired objective, that can only be achieved by the dissemination within public administrations of a set of management principles and techniques allowing Morocco to set up an effective and efficient management of administrative affairs. The same goes for the advent of currents that promote the application of the principles of good governance and new public management, through the adoption of management standards and practices borrowed from the private sector. According to this logic, Moroccan public administrations have become aware of the importance of adopting internal audit as a mean to improvt their performance.
\end{abstract}

Keywords: Internal audit; modernization of public administration; new public management; good governance.

\section{INTRODUCTION}

The will to modernize public administrations following the example of the adoption of good governance practices and the new public management as conjectured by the Moroccan constitution measures of 2011 and with the successive reforms of the public administrations' context, they have seen their attributions and their field of intervention widen.

Also, the context of Moroccan public administrations does not cease to record important changes. The objective is to improve their performance according to a performance approach based on the implementation of management tools borrowed from the private sector.

Faced with this new orientation, Moroccan public administrations are now subject to institutional standards of quality, transparency, accountability and responsibility. As a result, the establishment of entities in charge of internal audit within public administrations draws its legitimacy from their capacity to modernize the sector, rationalize it in a perspective of continuous improvement.

On this basis, Moroccan public administrations are called upon to set up an internal audit function, thus enabling them to strengthen their performance while guaranteeing better risk management and cost optimization. The objective is to enable the introduction of a new management mode based on a modernization approach.

The question that arises is: How does internal audit constitute an effective mechanism in the process of modernization of Moroccan public administrations? 
To answer this question, we will discuss in detail, after having addressed the definition of internal audit, the contributions of the New Public Management (NPM) to administrative management and the adequacy of its principles with the characteristics of internal audit. Finally, we will address internal audit as a tool for modernizing public administrations.

\section{WHAT IS INTERNAL AUDIT?}

Initially limited to the field of financial information, auditing has gradually broadened its scope of intervention to meet the changing demands of verification. Initially devoted to the financial and accounting verification of companies, auditing soon became part of the public sector.

The new public management and the objective of modernizing the public administration played in favor of the implementation of internal auditing, perceived as a real lever for modernization and optimization of management, making it possible to evaluate performance and to have reliable information on achievements in order to detect weaknesses and inefficiencies.

Based on the literature review of auditing, we will retain the general definition as well as the one specific to internal auditing.

"The audit is a procedure that consists of ensuring the completeness, sincerity and regularity of a company's accounts, vouching for them to the company's various interested partners and, more generally, passing judgment on the quality and rigor of its management" (Larrouse dictionary).

In English and according to the Cambridge dictionary, audit is defined as follows "to make official examination of the accounts of a business and produce a report".

It is clear that the word audit generally refers to the examination of the accounts of a company and their quality.

From its Latin origins (audio, audire: to listen) the word audit has undergone profound changes to cover all business activities. But if we call it "internal audit" refers to a specific function that we will try to define in what follows.

On the occasion of the 58th International Conference, the IIA Board of Directors approved a new definition of internal auditing at its meeting on June 26, 1999: "Internal auditing is an independent, objective assurance and consulting activity designed to add value and improve an organization's operations. It helps an organization accomplish its objectives by bringing a systematic, disciplined approach to evaluate and improve the effectiveness of risk management, control, and governance processes.

"Internal auditing is an independent, objective activity that provides assurance on the effectiveness of an organization's operations, advises on improvements, and helps add value. It helps the organization achieve its objectives by systematically and methodically evaluating its risk management, control, and governance processes and making recommendations to improve their effectiveness" (IFACI, 2013, P15).

\section{The NeW Public Management (NPM) AND THE MODERNIZATION OF PUbLIC ADMINISTRATION IN MOROCCO}

The management of a public administration is different from that of a company. Traditionally, the public sector is marked by its own particularities of rigidity when it comes to evolution and managerial dynamics. However, there are common points such as human resources management, project management, financial management, etc. But public sector management remains very specific. It must adapt to an environment, to the multiplicity of actors and institutions, to territories and to varied competencies. It must also adapt to a very dense 
legislative and regulatory framework (Constitution, laws governing the State and its institutions, finance laws, etc.).

Public administrations are governed by obligations of a political and legal nature. This strongly marks the legitimacy of administrative services which are based on the respect of principles. This "primary" legitimacy is increasingly complemented by another form of legitimacy called "secondary" where those responsible for strategic segmentation and policy orientations seek public recognition from citizens as a result of the quality of services offered. According to Maria Bonnafous-Boucher and Yvon Pesqueux 2006: "One of the characteristics of the New Public Management is to insist on the secondary legitimacy of public sector organizations by focusing attention on the search for organizational efficiency and the improvement of the quality of goods and services offered by administrative services.

The emergence of the New Public Management (NPM) was a leap towards modernity and efficiency for public administrations, defined as a model of public management that refers to the new governmental trends of the 1980s related to recent reforms undertaken in the public sector in order to establish a culture of excellence and performance (Steane, Dufour, and Gates 2015).

In this sense, the New Public Management insists on the legitimacy of administrative services according to an approach based on a strong preoccupation with the performance of the services provided (Laufer and Burlaud, 1983; Hood, 1991; Pollitt and Bouckaert, 2000; Gruening, 2001, cited by Kaoutar Lahjouji 2018) by allowing for new management modes. It is in the perspective of establishing a performance culture in public administrations that the New Public Management emerged. It has proposed a new ideological orientation to the management of public affairs by providing a set of managerial tools and practices from the private sector. The New Public Management focuses on the decision-making process, the setting of objectives and the implementation of monitoring and performance measurement tools rather than the respect of procedures and rules that characterizes the traditional management of public administrations (Donald J. Savoie, 2016. Cited by Kaoutar Lahjouji 2018).

Today, public administrations are called upon to be more efficient. For this, the private sector following its innovative practices seems to provide an effective management model against the bureaucracy symbol of all dysfunctions (F. Gangloff, 2009).

Theoretically, the New Public Management is perceived as a management model that draws its foundations from many currents of thought (the current of organizational development, neo-institutional theory, theory of organizations, theory of diffusion of innovation, agency theory, etc.) and that adheres to the school of public choice which is based on the rational and egoistic behavior of individuals (i.e., the idea that the politician becomes an egoistic economic actor like all others. He seeks to maximize his personal utility, determined by the factors of ideology and power). (AMAR A., BERTHIER L 2007).

Hood (1995) lists seven elements that refer to the New Public Management:

- The shift to the disaggregation of the public sector into strategic units organized by "edible" product;

- The shift to competition between public and private organizations;

- Insistence on management practice styles from the private sector,

- Insistence on more rational management of resources;

- Increased control of public organizations by visible managers exercising discretionary power; 
- A shift toward explicit performance standards and measures

- The implementation of indicators to measure results.

In this article, we are interested in the contribution of the 3rd and 5th elements, which refer respectively to the new management practices and the control of public organizations. This refers to the current of "managerialism", an ideology according to which the use of modern management methods through the adoption of rational formulas leads organizations to an efficient use of resources to achieve their objectives. Thus, public administrations today must establish a culture of rationalization of their activities, which makes them managed and run according to the operating modes of private companies, while mobilizing management practices that explain its organic singularity and purpose related to decentralization, disaggregation and disorientation (Thompson et al. 1995).

This consequence aims at translating the management tools and techniques of the private sector to apply them in the public sector by adopting the most efficient techniques (Rainey, 1990); this approach has forced public administrations to verify their bureaucratic management modes stemming from classical management (Auby, 1996, Hood, 2005, Parenteau, 1994, Rainey, 1990), the objective of which is to satisfy the demands of their democratization in order to bring them closer to the citizens.

In Morocco, the reform of the administration is becoming an imperative for the efficient management of public resources. Since the end of the 90s, many initiatives have been taken to reform the public administration, following the perception of its failure and the need for a modern administration capable of meeting the challenges of sustainable development undertaken by the Kingdom. Therefore, in order to meet these requirements, modern management mechanisms and rules have been introduced into government policies as defined by the good management pact designed in 1998. It aims at moralizing the public administration, rationalizing its management, and communicating and opening up to the environment (Kaoutar Lahjouji 2018).

Morocco, like developing countries, has joined this movement to establish the principles of NPM. Indeed, efforts have been made through administrative reform with the establishment of the foundations of a new public administration through NPM practices that try to reach all public sectors. Indeed, His Majesty King Mohamed VI, during his speech at the opening of the first session of the current legislature on October 14, 2016, specified that the introduction of a new management mode was initiated following the identification of several dysfunctions of weak governance and insufficient productivity. The adoption of this new mode of management within the Moroccan public administrations was outlined following the Royal speech of July 29, 2017, which pushed public officials in this case territorial officials to put in place active governance models as well as the setting of ambitious objectives to better meet the expectations of citizens and this as part of the implementation of the principles of New Public Management (Lahcen ELAMRAOUI 2018).

The reforms of the New Public Management have affected all public sectors through a sustained change and aimed at improving their effectiveness, equity and efficiency. Indeed, at the level of strategic segmentation, great importance has been given to the implementation of strategic planning combined with sectoral strategies with a territorial variation. At the level of governance, we note a separation of planning and operational functions. In this context, we note an evolution in the management mode characterized by the predominance of the State, which is responsible for the implementation of policies and which subsequently intervenes in their execution, towards a mode based on advanced deconcentration, notably through the implementation of the principles of advanced regionalization.

Another characteristic of the New Public Management is that of performance and evaluation of the results obtained under the application of the Organic Law rules on Finance Laws (LOLF). Indeed, public institutions have a reporting and evaluation system based on accurate financial indicators. Thus, these indicators form the 
basis for decision-making by central services, since they base their budget execution on the rate of commitment and issuance in order to make budgetary decisions, notably the increase or reduction of resources allocated to an organization. In addition, the three-year program budget, which replaces the annual budget, was adopted with the objective of correlating the allocated funds with the actions to be carried out in order to achieve the set objectives.

In order to meet the challenge of introducing the principles of the New Public Management in public administrations, it is essential to raise awareness among the administrative stakeholders so that they take part in this new management method in order to encourage them in the consecration of the entrepreneurial spirit within the public administration. However, a set of performance indicators must be designed and implemented to better manage activities. Performance is the result of a combination of effectiveness and efficiency, which requires the adoption and implementation of good governance standards. This can only be achieved through the involvement of agents and their degree of responsibility, knowing that good governance is based on the establishment of an effective and fluid information and communication system. In addition, the agents are called to adopt a proactive position that meets the demands of the citizens as well as the orientation of their functions rather than the execution of tasks (Lahcen ELAMRAOUI 2018).

\section{THE NMP AND INTERNAL AUDIT IN PUBLIC ADMINISTRATIONS WHAT REGULATORY SUPPORT?}

The application of the provisions of paragraph 2 of Article 1 of the Constitution, an article that refers to the responsibility and accountability of public officials, originates from the principles of the New Public Management, currently considered the basis on which the modernization of public administrations is based. This is because it obliges public officials to be accountable for their management.

Consequently, the internal audit, given its compatibility with the principle of accountability and its ability to provide the expected results, is more necessary than ever for Moroccan public administrations (Otman AZZARRADI 2018).

Under the provisions of the new constitution of 2011, including Articles 42, 50, 85, and 132, Moroccan public finances have undergone profound reforms embodied in the Organic Law No. 130-13 on the Finance Law, which stipulates in Article 66 of LOF No. 130-13 that the draft bill for the settlement of the finance law must be accompanied by the performance audit report. Similarly, all ministerial departments and public institutions must undergo a performance audit once every three years. This is a step towards independent and objective evaluation of the relevance of objectives, the reliability of the measurement system through performance indicators, and the analysis of the results of an organization in terms of effectiveness and efficiency, the assessment of internal control systems, etc.

In the same context, Decree $\mathrm{n}^{\circ} 2.07 .1235$ of November 4, 2008 on the control of State expenditures, aims to ensure that authorizing departments that meet the regulatory criteria and that have undergone an evaluation of their management capacity, benefit from modulated expenditure control. This is within the framework of an audit carried out by the General Inspectorate of Finance (IGF) by the General Treasury of the Kingdom (TGR) or any other inspection or control entity accredited for this purpose by order of the Minister of Finance. Among other things, it has become essential for authorizing officers to set up internal control and audit structures.

\section{INTERNAL AUDIT, A TOOL FOR MODERNIZING PUBLIC ADMINISTRATIONS}

In the early 1970s, public institutions experienced an accelerating crisis of citizenship and democracy (Hamel and Jouve, 2006), due to the inability of the state management mechanisms in place to respond to social 
demands. This situation was compounded in the early 1980s by the worsening of public deficits following a financial crisis. This situation was the trigger for dysfunctions affecting the management of public affairs such as lack of efficiency, cumbersome administrative procedures, lack of transparency and coordination between all services and inconsistent management of flexibility of the administration. A situation that has led governments towards deregulation to respond to social pressures in the context of the search for a managerial alternative for the management of public finances that modern management methods from the private sector have been adopted to gradually put in place the most common management tools and techniques borrowed from the private sector and to be able to adapt them to the context of public administrations for the emergence of New Public Management. In particular, internal auditing plays an important role in the administrative reform process that has been underway for several years.

The New Public Management is a difficult concept to grasp because of the multiplicity of forms it can take. It emphasizes efforts to modernize the State and develop an entrepreneurial spirit in the public sector by introducing the notion of "Entrepreneurial Government". According to Audrey Bécuwe (2005), the New Public Management is based on the idea of designing a hybrid mode of management of public administration, on one hand, by adopting more and more innovative tools and techniques from the private sector and, on the other hand, by giving less importance to the application of administrative or even bureaucratic rules and procedures.

Stemming from contemporary management theories aimed at the private sector, New Public Management, also called New Public Management (NPM), is first and foremost a form of "post-bureaucratic" management, adopted gradually since the 1980 s by OECD countries wishing to modernize their public administration (Florence Piron 2003).

The New Public Management emphasizes efficiency, quality and effectiveness of the services provided (Laufer and Burlaud, 1983; Hood, 1991; Pollitt and Bouckaert, 2000; Gruening, 2001, cited by Kaoutar Lahjouji 2018) through the implementation of new management practices. Following the objective of establishing a performance culture that the New Public Management took place. It has brought ideological support to public sector management by providing innovative tools and techniques for the transfer to new modes of governance.

In this sense, the adoption of the principles of the New Public Management and the application of the orientations of the new constitution, whose objective is the implementation of a culture of excellence within the administrations by a result-oriented management and accountability, remains dependent on the effectiveness of the systems of control posteriori, of which the internal audit is part (El Hilali Karima 2019).

The local authorities have, in their field of competence, multiple attributions which are transferred to them. Currently, they carry out various vital activities for the citizens. Moreover, they are financed by funds collected from taxpayers and also take decisions with a strong impact on the daily life of citizens. Therefore, the exercise of control and verification activities, including internal and external audit functions, is increasingly important (Dees, 2012).

In fact, the main mission of internal audit is to evaluate the internal control systems put in place by the organization in order to control the risks associated with the achievement of objectives. The advent of internal audit in public administrations can be explained by several factors: firstly, the increasing restriction of budgetary resources and the need to control financial commitments; secondly, the controls exercised by the control bodies and their recommendations; and finally, the need to put in place an effective internal control and risk management system.

Moreover, the performance desired by administrative managers depends on the establishment of a structure responsible for internal audit (Unegbu and Isa Kida 2011). It appears to be an effective tool that allows a public administration to modernize its management style. 
However, the establishment of an internal audit function in the organization chart of public administrations, according to international standards, allows managers to benefit from the added value it generates. They start from the logic that the objectives of internal auditing are in harmony with the peculiarities of the public sector, peculiarities that derive from the growing need for oversight of public management, the increasingly complex context of the administration and the lack of citizen trust.

According to the Institute of Internal Auditors of Canada (2014), internal auditing operates in three value streams rooted in the attributes and strengths of the function:

As a source of protection: the internal audit function participates in administrative oversight, providing assurance to government officials that their risk management systems and practices are well designed and operating effectively. Internal auditing is also an independent and objective diagnostic tool that allows citizens to be assured of the degree of oversight, accountability and control of the management of public affairs. It contributes to the preservation of the reputation and the reinforcement of the confidence of the public sector.

As a source of learning: the internal audit function provides elected officials and administrative managers with accurate and detailed information and enables them to acquire knowledge and expertise in the areas of management, risk management and control. In this way, internal audit contributes to the training of senior managers in the discharge of their management responsibilities.

As a source of operational advice: Internal auditing provides elected officials and administrative managers with honest, reliable, and relevant advice on various aspects of public administration management.

To varying degrees, public administrations are confronted with the need to question their organizational and management methods, not in order to sacrifice to a fashion, but to reform themselves by making their evolutions of all kinds which today mark the management of organizations, among which the internal audit considered as a lever for modernization (Michel POISSON 1989).

\section{CONCLUSION}

Through this modest contribution, we can conclude that it is clear that it is necessary to inject in the public sector stuctures a spirit that favors the introduction of tools of all kinds that allow its modernization. Indeed, the adaptation of public administrations to the new challenges of the environment (decentralization, globalization, development of ICTs, etc.) and to the expectations of citizens is becoming an obligation. In this approach, we have explained the role of internal audit as a means to modernize the management of public administrations following its contributions in terms of control and implementation of the principles of good governance and new public management NPM.

Morocco is among the countries that have undertaken measures to modernize public administration within a global NPM framework. It remains to design and implement good practices for its adoption in order to achieve the objectives set, the purpose of which is not to make public services disappear but to improve them (Bartoli, 2005). In this perspective, internal auditing becomes central to the legal and legislative provisions of the public sector as a whole. It plays an essential role in the proper functioning of the public sector, since it is one of the essential means of ensuring the regularity, efficiency and performance of public services.

It remains to make public officials aware of the need to adopt and the added value of internal audit as an effective mechanism for modernizing public management. However, the process of setting up the internal audit must correspond to the international standards established in this sense and guarantee the function the objectivity 
and independence necessary to be able to engage as appropriate in the process of implementation and conduct of missions to achieve the expected objectives.

\section{REFERENCES}

[1] AMAR A., BERTHIER L., « Le nouveau management public : avantages et limites », Gestion et Management Publics, vol.5, Décembre 2007.

[2] Audrey Bécuwe 2005. A.T.E.R., IAE de Lyon 3, Rationalité Et Management Public de la rationalité limitée d'Herbert Simon, à la rationalité encastrée Actes du Colloque RECEMAP - Les Grands Auteurs en Management Public.

[3] Bartoli A. \& Blatrix C. (2015), "Management dans les organisations publiques : défis et logiques d'action”, 4ème édition, Dunod éditeur, paris, 2005

[4] Conseil de l'Europe, Comité directeur sur la démocratie régionale et locale, (2007), Audit interne aux niveaux Local et Régional.

[5] change ». Journal of Organizational Change Management 28 (2): 263- 70.

[6] Dees M. (2012), Le vérificateur dans le secteur public : Le trait d’union de l'administration publique, Télescope, vol.18, $\mathrm{n}^{\circ} 3$, p.8-32.

[7] Discontinuity: Managerial Rhetoric in Turbulent Times ». Personnel Review. 1995.

[8] El Hilali Karima (2019). « L'adoption de l'audit interne : vers une amélioration de la gouvernance des collectivités territoriales marocaines », Revue du contrôle, de la comptabilité et de l'audit.

[9] Florence Gangloff, Le nouveau management public et la bureaucratie professionnelle, publié dans "La place de la dimension européenne dans la Comptabilité Contrôle Audit, Strasbourg : France,2009.

[10] Florence Piron 2003. « La production politique de l'indifférence dans le Nouveau management public », Anthropologie et Sociétés, vol. $27, \mathrm{n}^{\circ} 3$, p. 50.

[11] Gestion publique. Les Presses de l'Université de Montréal, p.167-172.

[12] Hamel. P et Jouve. B. (2006). Un modèle québécois ? Gouvernance et participation dans la

[13] Hood, Christopher. 1995. « The New Public Management in the 1980s: Variations on a

[14] Improving Public Sector Management, in Journal of Emerging Trends in Economics and Kaoutar Lahjouji, Kaoutar El Menzhi (2018). Le Nouveau Management Public au Maroc, quels apports ? hal-01801445.

[15] Institut des auditeurs internes du Canada (IAI Canada) (2014). L'optimisation du pouvoir de l'audit interne dans le secteur public.

[16] Lahcen ELAMRAOUI (2018). Apport du nouveau management public dans la consécration de la performance de l'administration publique marocaine. Revue du Contrôle de la Comptabilité et de l'Audit.

[17] Management Sciences (JETEMS) 2 (4), p.304-309.

[18] Maria Bonnafous-Boucher \& Yvon Pesqueux, 2006. "Décider avec les parties prenantes," Post-Print hal-00479620, HAL. Handle: RePEc:hal:journl:hal-00479620.

[19] Michel POISSON (1989). L'AUDIT Un outil de progrès au service du secteur public. La Revue administrative, 42e Année, No. 250 (JUILLET AOUT 1989), pp. 370-377.

[20] Otman AZZARRADI (2018). Professionnalisation de l'audit interne dans l'administration publique marocaine : réel besoin ou illusion de contrôle ? Revue du Contrôle de la Comptabilité et de l'Audit.

[21] Steane, Peter, Yvon Dufour, et Donald Gates. 2015. « Assessing impediments to NPM Theme ». Accounting, Organizations and Society 2- 3 (20): 93- 109.

[22] Thompson, Paul, Julia O\&amp, apos, et Connell Davidson. 1995. « The Continuity of

[23] Unegbu, A O. et Isa Kida, M. (2012). Effectiveness of Internal Audit as Instrument of

[24] Yvon Pesqueux 2006. Master Professionnel Spécialité Prospective, Stratégie Et Organisation, Fiche De Lecture Paradoxes De La Gestion Publique, Yves Emery Et David. 